ВАСИЛЕНКО Ирина Алексеевна - доктор политических наук, профессор кафедры российской политики факультета политологии Московского государственного университета им. М.В. Ломоносова (119991, Россия, г. Москва, Ломоносовский пр-кт, 27, корп. 4 «Шуваловский»; vasilenko.irina@ mail.ru)

\title{
«УМНЫЙ ГОРОД» В ЦИФРОВОМ ОБЩЕСТВЕ 5.0: СОЦИАЛЬНО-ПОЛИТИЧЕСКИЕ И ГУМАНИТАРНЫЕ РИСКИ ЦИФРОВИЗАЦИИ ОБЩЕСТВЕННОГО ПРОСТРАНСТВА
}

\begin{abstract}
Аннотация. Статья посвящена исследованию проблем формирования «умного города» в цифровом обществе на основе пятой технологической революции, которая несет с собой широкое внедрение инновационных смарт-технологий в социум, среди которых можно выделить большие данные, искусственный интеллект, дополненную реальность. Автор считает, что сегодня политологи должны не только сконцентрировать внимание на блистательных перспективах “цифрового мира", но и всесторонне рассмотреть его возможные политические вызовы и риски, обусловленные внедрением смарт-технологий в общественное пространство, что связано с дегуманизацией общественных отношений в ответ на предельную технологизацию общества. Автор приходит к выводу о необходимости гуманитарной экспертизы при внедрении смарт-технологий в общественное пространство, развития ответственного стратегического планирования в реализации государственной политики формирования цифрового общества. Ключевые слова: цифровое общество, пятая технологическая революция, смарт-технологии, инновации, политические риски
\end{abstract}

Ч еловечество стоит на пороге пятой технологической революции, стремительно приближающей эпоху цифрового суперинтеллектуального общества 5.0 , которое обещает нам невиданное прежде материальное процветание и комфортное проживание в «умных городах». Ученые утверждают: интеллектуальные технологии (Smart Technologies) сделают общество «умным». Так родилось понятие «суперинтеллектуальное общество» - общество, основанное на применении инновационных smart-технологий.

Необходимо отметить, что сегодня концепция цифрового общества, или суперинтеллектуального общества (Super Smart Society), Общества 5.0 (Society 5.0) рассматривается современными учеными как ответ на актуальные вызовы современности и продолжение известной концепции Общества 4.0, которое формируется четвертой промышленной революцией, основанной на передовых цифровых технологиях, таких как большие данные, искусственный интеллект, дополненная реальность. Однако Общество 5.0 уже не ограничено только производственным сектором, а призвано решать социальные проблемы с помощью интеграции физического и киберпространства, что приведет к стремительному развитию «умных городов».

Очевидно, что для перехода к новому экономическому укладу в «умном городе» будущего необходимы серьезные изменения в государстве и обществе. Формирование цифровой экономики поможет создать набор инструментов, которые при правильном применении способны решить многие социально-политические проблемы. Но для этого необходима целенаправленная государственная политика в области высоких технологий. Например, в Японии существует специальное профильное ведомство, которое занимается высокими технологиями - Национальный институт продвижения цифровой экономики и цифрового общества (Japan Institute for Promotion of Digital Economy and Community, JIPDEC). Только информационно-коммуникационный сектор уже 
обеспечивает в стране 9\% ВВП и 7\% рабочих мест (в Евросоюзе - $4 \%$ и $3 \%$ соответственно). Здесь уже есть примеры технологических решений, направленных на реализацию стратегии Общества 5.0. Так, корпорация Mitsubishi Electric развивает платформу промышленной автоматизации $e$-F@ctory, позволяющей создавать «умные» фабрики и заводы. Это интеллектуальные промышленные системы или «умное производство» на основе искусственного интеллекта и распределенных вычислений. Компания Fujitsu производит носимую электронику, которая позволяет применять новые бизнес-модели в здравоохранении. Toshiba работает над альтернативной энергетической системой, которая поможет снизить зависимость от централизованной генерации электроэнергии за счет использования маленьких локальных источников ${ }^{1}$.

Не менее амбициозная программа формирования «цифрового общества 5.0» разработана и реализуется в Сингапуре с начала 2014 г. Главная идея сингапурской концепции сформулирована в жанре национального манифеста: «Сингапур стремится создать “умную нацию” - более организованное и сплоченное сообщество с высоким уровнем жизни, создающее больше возможностей для творческого развития каждого. Понятие “умный” в этой концепции означает не степень сложности развития технологий, а то, насколько общество способно использовать технологии для решения своих проблем и ответов на вызовы времени. Граждане, а не технологии находятся в центре нашего видения “умной нации”!»2

Программа «Умная нация» направлена на решение нескольких ключевыхзадач, которые и представляют системный подход к внедрению смарт-технологий в социум. Первое направление носит символическое название «совместные креативные решения для каждого» (Co-creating Solutions with Anyone for Everyone). Цель - объединение всех институтов общества (университетов, лабораторий, предприятий, правительственных органов) для совместной разработки креативных инновационных решений развития города. Второе направление - «поддержка больших идей» (Opportunities for Your Big Ideas to Be Supported). Сегодня в Сингапуре построена хорошая экосистема стартапов, которая воплощает в себе благоприятную предпринимательскую культуру, где поощряются эксперименты. Третье направление - «умная мобильность» (Smart Mobility): создание более удобной транспортной инфраструктуры, корректировка маршрутов проезда, предоставление более широкого доступа к информации о транспорте в реальном времени, чтобы граждане Сингапура могли лучше планировать свои поездки. Четвертое направление - «умное проживание» (Smart Living), предполагающее внедрение смарт-технологий для комфортного проживания граждан в «умном доме».

Современная цифровизация Сингапура достигла впечатляющих масштабов: здесь создано единое информационное пространство, превратившее город в глобальный центр, поставляющий информационные услуги по всему миру. Благодаря реализации программы IT 2000 и проекта Singapore ONE (ONE Network for Everyone) была создана общенациональная широкополосная сеть для предоставления мультимедийных услуг, и сегодня к ней подключено около 90\% территории страны, включая 99\% офисов, школ и домов ${ }^{3}$. Помимо этого, в Сингапуре (впервые в мире!) широко используются беспилотные автобусы в

\footnotetext{
${ }^{1}$ Уэмура Н. Стратегия «Общество 5.0». Доступ: https://iz.ru/630395/tcifrovaia-ekonomika-opyt-iaponii (проверено 11.08.2019).

2 Smart Nation Singapore. URL: http://www.pmo.gov.sg/Newsroom (проверено 20.01.2019).

3 Connected Singapore. A new blueprint for infocomm development. URL: https://www.ida.gov.sg/ / media/Files/About\%20Us/Corporate\%20Publications/Past\%20Infocomm\%20Plans/Connected.pdf (проверено 20.01.2019).
} 
системе городских коммуникаций, а в строительстве применяется $3 D$-печать при возведении жилых домов: это помогло более экономично и эффективно решить квартирный вопрос на острове для малообеспеченных жителей. Некоторые районы Сингапура уже сейчас соответствуют стандарту «умного дома» (Smart Building), а к 2020 г. $80 \%$ всех зданий должны соответствовать стандарту энергоэффективности «GreenMarkCertified»1.

Таким образом, уже первые практические шаги по формированию «умного города» в Обществе 5.0 формируют более высокий уровень жизни и комфорта для граждан, креативные решения сложных социальных и экологических проблем общества с помощью инновационных технологий. Однако при этом внедрение смарт-технологий в социум уже сейчас сопровождается целым рядом сложных антропологических и гуманитарных проблем, которые обозначились практически во всех странах, где они начали использоваться. Новые горизонты цифрового общества притягивают и пугают: мы хотим знать, каковы опасности и риски этого амбициозного проекта, который мы выбираем сегодня? У новых интеллектуальных технологий огромные возможности, но каковы их границы? Насколько они гуманны?

Вот вопросы, на которые общественные науки в ближайшее время должны найти ответы. Стремительная технологизация общественного пространства уже сегодня сопровождается опасностями и рисками дегуманизации общественных отношений, о которых с тревогой пишут политологи, экономисты, социологи, психологи и общественные деятели. В цифровом обществе концентрация таких технологий достигнет исторического максимума, поэтому вопрос о том, как предотвратить возможные негативные последствия внедрения цифровых технологий в общественное пространство, важно решить уже сегодня, чтобы завтра не было катастрофически поздно. Поэтому сегодня ученые должны сконцентрировать внимание не только на блистательных перспективах «цифрового мира», но и всесторонне рассмотреть его возможные политические вызовы и риски.

Основные научные дискуссии фокусируются вокруг политических рисков при использовании цифровых технологий в обществе, связанных с дегуманизацией общественных отношений, потерей креативности человека и общества в ответ на предельную технологизацию общественного пространства. Требуют широкого общественного обсуждения социально-политические и гуманитарные вопросы развития такого общества, и среди них вопрос о полном переходе граждан на цифровые носители.

Прежде всего, в странах, которые дальше всех продвинулись с внедрением цифровых технологий, основной упор в системе образования был сделан на развитии технических наук, во многом в ущерб гуманитарным, что привело к сильной технологизации общественного сознания. Ярким примером здесь является Сингапур: в университетах этого города-государства единственным популярным гуманитарным направлением сегодня является лингвистика изучение иностранных языков. Культ техники, точных наук и предпринимательства обернулся тем, что литература и искусство, фундаментальные научные исследования перестали интересовать сингапурцев: согласно социологическим опросам, лишь $40 \%$ населения Сингапура прочитали хотя бы одно литературное произведение за год (в США, к примеру, эта цифра составляет 70\%) ${ }^{2}$. Между тем с точки зрения грамотности Сингапур - одна из самых продвинутых стран в мире: уровень грамотности здесь достиг 98\%.

\footnotetext{
${ }^{1}$ Smart Nation Singapore. URL: http://www.pmo.gov.sg/Newsroom (проверено 20.01.2019).

2 Сингапур придумывает, как заставить граждан полюбить литературу. Доступ: http://ibusiness. $\mathrm{ru} / \mathrm{blog} /$ experience/42728? utm_source=\&utm_medium $=\& u t m \_c a m p a i g n=$ pochitayte-o-tom--kak-vsingapure-budut-p (проверено 20.01.2019).
} 
Уже сегодня парадокс технологизации в этой стране, быстрее всех продвигающейся по пути формирования «цифрового общества», проявился в том, что в обществе начали преобладать квалифицированные профессионалы, но очень мало творческих и талантливых людей. Научные открытия, разработка новых перспективных направлений развития науки не увлекают сингапурцев: среди них практически нет выдающихся ученых ни в одной фундаментальной области знаний. И это стало по-настоящему серьезной проблемой: ведь именно интеллектуальный капитал является главным источником богатства и процветания современных государств. Сингапур вынужден покупать таланты - приглашать креативных иностранных специалистов для развития своей страны [«Умный город» XXI века... 2018: 6-7].

Эти последствия технологизации Сингапура не могут не настораживать: важно не повторить такую ошибку при формировании цифрового общества в нашей стране, где традиционно всестороннее развитие человека было в центре системы образования. Многие отечественные политологи уже сегодня с тревогой пишут об общей тенденции к дегуманизации, свойственной цифровой технологической революции [Малышева 2018: 44]. Сушествует серьезная опасность, что человек в цифровом обществе станет частью математического уравнения, по которому будет рассчитываться перераспределение общественного богатства на основе исключительно количественных данных. Его роль в цифровой экономике будет ограничена функцией «социального клиента», претендующего на свою скрупулезно высчитанную долю общей массы социальных услуг.

Не менее важным является вопрос об ограничении свободы человека с развитием цифровых технологий, особенно при полном переходе граждан города на цифровые носители. Необходимо напомнить, что проблема ограничения свободы человека при развитии новых технологий - одна из вечных в истории человечества. И предложение обменять часть свобод на безопасность неизбежно возникает при каждом новом повороте в развитии технологизации общественного пространства. Здесь хочется процитировать известного российского экономиста Александра Аузана: «Не меняйте свободу на безопасность проторгуетесь. Причина проста: когда вы меняете свободу на безопасность, вы снимаете тот уровень притязаний к государству, который заставляет работать наиболее эффективную часть формулы, - вероятность наступления наказания. Вы получите меры наказания, которые будут применяться как устрашение, а не как возмездие за реально совершенное преступление, эффект будет дважды отрицательный: преступники не понесут наказание, а невинные граждане будут жить в атмосфере страха. Как писал Бенджамин Франклин, “те, кто готов пожертвовать неотъемлемой свободой ради временной безопасности, не заслуживают ни свободы, ни безопасности”» [Аузан 2014: 21].

Сегодня от лица духовной власти в России Патриарх Московский и всея Руси Кирилл также выражает беспокойство по поводу того, что цифровые технологии способны ограничить свободу человека. Действительно, идея полностью отказаться от наличных средств оплаты и перейти на безналичный расчет несет в себе риски: «У нас есть горячие головы, которые с восторгом говорят о необходимости ликвидировать наличные деньги и перейти только на электронные карточки. А если вдруг в какой-то момент исторического развития доступ к этим карточкам будет открываться в ответ на вашу лояльность?»1

Такой «тоталитарный» сценарий развития цифрового общества мы должны предотвратить уже сегодня. Этот очень важный политический вопрос необхо-

\footnotetext{
${ }^{1}$ Патриарх Кирилл видит в развитии цифровых технологий угрозу для свободы человека. Доступ: https://www.rbc.ru/rbcfreenews/5a521d779a7947ecf4f67d3a (проверено 11.08.2019).
} 
димо обсуждать на самых разных дискуссионных площадках: мнение общества нельзя игнорировать при строительстве цифровой экономики. Цифровая революция не должна разрушать гуманистические традиции российского общества: мы должны искать пути использования цифровых технологий с целью развития уже сложившегося в России общественно-экономического уклада. Поэтому не стоит слепо копировать зарубежные образцы внедрения смарт-технологий в общественное пространство: надо искать собственные варианты с учетом своих социокультурных традиций и особенностей национального менталитета. Как справедливо отмечает С. Глазьев, «каждая страна должна строить свой вариант цифрового общества, с учетом собственных традиций и этических норм»1.

Хочется обратить внимание, что сегодня некоторые известные деятели культуры выказывают негативное отношение к тому, как некорректно цифровые технологии внедряются в структуру общественного пространства, особенно в архитектуру домов: современному человеку все более активно предлагают пожертвовать приватностью ради удобств. Создавая «умный дом», архитекторы настолько переключили свое внимание на создание удобств за счет технологий, что перестали замечать их возможную опасность. При этом международные корпорации, производящие электронику, смотрят на архитектуру как на источник для внедрения новых технологий и получения прибыли и также закрывают глаза на проблему их опасности для человека. Современный «умный дом» оснащен множеством сенсоров, которые отслеживают и записывают действия людей, находящихся в доме. Например, современная система отопления с элементами «умного дома» Nest использует датчики движения для фокусировки инфракрасных лучей именно на людях, которые передвигаются по дому. Сложно предположить, что человек будет особенно счастлив, если в «умном доме» у него не останется никакой личной жизни.

Сегодня массмедиа все чаще сообщают об утечках данных, о новых системах слежки, о прослушивании личных мобильных телефонов: слишком много места в нашей жизни занимают технологии, нарушающие конфиденциальность. При этом некоторые исследователи полагают, что исчезновение личной тайны в XXI в. - это шокирующее открытие, но с ним надо смириться: надо забыть о конфиденциальности [Rengel 2013]. Другие настроены еще более радикально: личную тайну вообще следует отменить, поскольку порядочному человеку скрывать нечего. С этим трудно согласиться: даже порядочному человеку хочется сохранять в секрете свои личные, финансовые или медицинские сведения. И компании, производящие информационные технологии, обязаны об этом позаботиться. Общество должно заставить их это сделать. Сегодня в Европе гражданские активисты 27 января отмечают День конфиденциальности данных (Data Privacy Day). Это прекрасная инициатива, и ее важно популяризировать, сделать международной. Иначе «умный дом» в цифровом обществе станет стеклянным аквариумом, а все мы все превратимся в «золотых рыбок» для кибервандалов.

Еще одна серьезная проблема будущего Общества 5.0 - дегуманизация общественного пространства в результате формирования технократического общества, что способно привести к настоящей антропологической катастрофе. Одним из первых эту антропологическую катастрофу технократического общества предсказал Эрих Фромм, назвав человека, погруженного в виртуальное зазеркалье, «моноцеребральным» - человеком одного измерения. Для моноцеребральной личности характерна определенная форма нарциссизма, при кото-

\footnotetext{
${ }^{1}$ Глазьев С.Ю. Великая цифровая революция: вызовы и перспективы для экономики XXI века. - Персональный сайт С.Ю. Глазьева. Доступ: https://glazev.ru/articles/6-jekonomika/54923-velikajatsifrovaja-revoljutsija-vyzovy-i-perspektivy-dlja-jekonomiki-i-veka (проверено 11.08.2019).
} 
рой все нацелено на достижение успеха. Сегодня успех - это возможность обладать суперновым. Эрих Фромм поставил точный диагноз моноцеребральному кибернетическому человеку, назвав его аутистом - больной личностью больного мира. Отличительные черты аутизма - неразличение живой и неживой материи, отсутствие привязанности (любви) к другим людям, использование языка не для общения, а для манипуляции, а также преимущественный интерес не к людям, а к машинам и механизмам. Если паталогические процессы распространяются на все общество, то люди теряют индивидуальный характер: тогда вся культура настраивается на этот тип патологии и находит пути и средства для ее удовлетворения [Фромм 2015: 467].

Психологи, нейробиологи и психотерапевты сегодня с тревогой пишут о том, что «цифровое слабоумие» в эпоху тотального увлечения человека гаджетами - это медицинский диагноз [Greenfield 2015]. Сам термин «цифровое слабоумие» (digital dementia) пришел из Южной Кореи, раньше всех вступившей на путь внедрения цифровых технологий. И врачи стали отмечать, что все большее число подростков, увлеченных миром гаджетов, страдают расстройством внимания, когнитивными нарушениями, подавленностью и депрессией. Более того, современные исследования нейробиологов показали, что в мозгу таких пациентов наблюдаются патологические изменения, схожие с ранней стадией слабоумия, обычно развивающейся в старости (что отмечено в фундаментальном труде нейрофизиолога, директора психиатрического госпиталя при университете в Ульме (Германия), основателя Центра нейронаук и обучения Манфреда Шпитцера [Шпитцер 2014]).

Понятно, что остановить технический прогресс нельзя: никто не хочет прослыть ретроградом, противником новых технологий. Но обществу необходимо знать о рисках, которые несут новые цифровые технологии подрастающему поколению. С одной стороны, эти технологии обеспечивают удобство и комфорт, ускоряют и облегчают многие виды деятельности. Но у новых технологий есть оборотная сторона: они опасны для детей и подростков, и это необходимо учитывать. Важно вовремя принять меры, чтобы оградить детей от тотального погружения в мир гаджетов, что реально угрожает им в цифровом обществе. Именно для этого нужна гуманитарная экспертиза при внедрении смарт-технологий в общественное пространство, и актуальная задача научной общественности сегодня - привлечь внимание государства и общества к этой проблеме.

Наш главный вывод состоит в том, что необходимо принять серьезные государственные меры, чтобы избежать политических рисков при формировании цифрового общества. Необходима опора на государственную стратегическую инициативу и государственный контроль, опирающийся на широкую гуманитарную экспертизу при внедрении смарт-технологий в общественное пространство. Сегодня назрела настоятельная необходимость в развитии ответственного стратегического планирования в реализации политики формирования цифрового общества со стороны государства как ключевого актора.

Вместе с тем научные дискуссии о предотвращении опасностей и рисков цифрового общества важно продолжить. И продолжить не только в научном формате, но и в вузовской аудитории, среди молодежи и студентов. Именно молодому поколению предстоит сформировать это общество, поэтому они должны сегодня разобраться в опасностях и рисках этого амбициозного интеллектуального проекта. 


\section{Список литературы}

Аузан А. 2014. Экономика всего. Как институты определяют нашу жизнь. М.: Манн, Иванов и Фербер. 150 с.

Малышева Г.А. 2018. О социально-политических вызовах и рисках цифровизации российского общества. - Власть. Т. 26. № 1. С. 43-46.

«Умный город» ХХІ века: возможности и риски смарт-технологий в городском ребрендинге (под ред. И.А. Василенко). 2018. М.: Международные отношения. $256 \mathrm{c}$.

Фромм Э. 2015. Анатомия человеческой деструктивности. М.: АСТ. 624 с.

Шпитцер М. 2014. Антимозг. Цифровые технологии и мозг. М.: АСТ. 288 с.

Greenfield S. 2015. Mind Change: How Digital Technologies Are Leaving their Mark on Our Brains. N.Y.: Random House. 368 p.

Rengel A. 2013. Privacy in the $21^{\text {St }}$ Century. Miami: Saint Thomas University School of Law. 268 p.

VASILENKO Irina Alekseevna, Dr.Sci. (Pol.Sci.), Professor of the Chair of Russian Policy, Faculty of Political Science, Lomonosov Moscow State University (bld. 4 «Shuvalovskij», 27 Lomonosovsky Ave, Moscow, Russia, 119991; vasilenko. irina@mail.ru)

\section{PROSPECTS OF FORMING A DIGITAL SOCIETY: SOCIO-POLITICAL AND HUMANITARIAN RISKS OF DIGITIZATION OF PUBLIC SPACE}

\footnotetext{
Abstract. The article examines the problems of the Smart City in the digital society, based on the results of the fifth technological revolution: the widespread incorporation of innovative digital technologies into the society, including big data, artificial intelligence, alternate reality, etc. The author suggests that political scientists should focus not only on the brilliant prospects of the digital world, but also consider its possible political challenges and risks of the incorporation of smart technologies into social life, such as the dehumanization of social relations as a result of the technologization of society. The author concludes that creating Society 5.0 requires the thorough analysis of the incorporation of smart technologies in public life, and a well-designed state strategy aimed at creating a digital society.
}

Keywords: digital society, fifth technological revolution, smart technologies, political risks 